\title{
X Congreso Ibérico de Agroingeniería

\section{Evaluación de diferentes sustancias químicas como repelentes del crecimiento radicular para su uso en mantas de riego subsuperficial}

\author{
A. Aldaz Lusarreta (P)르, Celia Ochoa Lizoain², R. Giménez Díaz ${ }^{3}$, M.A. Campo Bescós ${ }^{3}$ \\ 1 Investigadora, Universidad Pública de Navarra, Departamento de Ingeniería; alaitz.aldaz@unavarra.es \\ 2 Estudiante, Grado en Ingeniería Agroalimentaria y del Medio Rural, Universidad Pública de Navarra; \\ ochoa.106935@e.unavarra.es \\ 3 Profesor, Universidad Pública de Navarra, Departamento de Ingeniería; miguel.campo@unavarra.es \\ rafael.gimenez@unavarra.es
}

\begin{abstract}
Resumen. El riego por goteo subterráneo ha despertado en los últimos años gran interés en el sector de la jardinería, un claro ejemplo son las mantas de riego con tubería de goteros integrados. Pese a que los emisores están protegidos por la manta, se sigue manifestando la obturación de goteros por las raíces del cultivo. Una manera de paliar la obturación es utilizar sustancias químicas adheridas directamente en la manta que repelan el crecimiento radicular. La presente investigación tiene como principal objetivo evaluar las diferentes imprimaciones de sustancias químicas como repelente radicular en prototipos de mantas de riego subsuperficial confeccionadas a partir de material de geotextil reciclado (moquetas feriales). Las sustancias químicas utilizadas han sido; mezcla de látex con fécula de maíz, a diferentes concentraciones y nanopartículas. Se evalúan tres testigos: dos productos comerciales y uno sin añadir sustancias químicas. Para cada tratamiento se confecciona, a partir del material reciclable, una pequeña bolsa, se siembra una semilla de maíz en el interior y se entierra a ras del suelo. Una vez que la planta alcanza su madurez, la bolsa se desentierra y fotografía. Por último, se evalúa la cantidad de raíces que han atravesado las paredes de la misma mediante análisis de imágenes y técnicas estadísticas.
\end{abstract}

Palabras clave. Riego localizado, riego subsuperficial, sustancias antienraizamiento.

\section{Introducción}

El interés en la utilización de riego por goteo subterráneo ha ido incrementando en los últimos años, sobre todo en el sector de la jardinería. Este sistema de riego presenta como ventaja el mejor aprovechamiento del agua de riego y de los nutrientes aplicados en ésta, lo que deberá resultar en una mejor calidad de los productos agrícolas. (Ayars et al. 1999). A pesar de ello, tiene un principal inconveniente que es la obstrucción de los emisores situados en el tubo de riego, debido a la intrusión de las raíces en ellos.

Este incremento en la utilización del riego por goteo subterráneo, ha dado paso a una nueva tecnología que consiste en aplicar este sistema en mantas de riego, la cual se adopta como una posible solución para el problema de la obturación de los emisores. Este tipo de técnica se basa en introducir el tubo de riego, con los emisores integrados, en la manta del material correspondiente. Presenta diferentes ventajas como son el ahorro de agua, una distribución uniforme de la misma por toda la superficie de riego y un suministro directo a las raíces del cultivo, entre otras. 


\section{CONGRESO IBÉRICO DE AGROINGENIERÍA \\ X CONGRESSO IBÉRICO DE AGROENGENHARIA \\ 3 - 6 septiembre 2019, Huesca - España}

Sin embargo, a pesar de que los emisores están protegidos por la manta, se sigue manifestando la principal limitación que presenta el riego localizado, y especialmente el subsuperficial sin manta. Es decir, la ocasional obturación de los goteros debido a su milimétrico tamaño. Pueden ser diversos factores los que provoquen dicha obstrucción; físicos: producidos por las raíces del cultivo que crecen y ciegan los emisores, y por la presencia de partículas sólidas, de origen orgánico (fitoplancton, algas, bacterias...) o inorgánico (arena, limo, arcilla...), que se encuentran en suspensión en el agua; químicos: precipitación de sales solubles, que proceden de agua o de fertilizantes, por evaporación del agua a la salida de los goteros; biológicos: acumulación de masas de macro y microorganismos (algas y bacterias) o por precipitados de óxidos de hierro y manganeso producidos por ciertas especies de bacterias (F. Martín de Santa Olalla y J. A. De Juan, 1993). Otras limitaciones añadidas a este sistema en mantas de riego son el elevado coste de las mismas, y el deterioro o la pérdida de la calidad del material enterrado.

Siendo la principal limitación del riego localizado y de las mantas de riego, la obstrucción de los emisores, existen diferentes formas de mitigar o moderar la intrusión de raíces en estos. Los goteros deben ser antisucción y tener una barrera física antirraíces.

Asimismo, igualmente importante, es realizar un adecuado manejo del riego. La frecuencia de riego es un factor fundamental para prevenir la intrusión radicular. El sistema radicular no invade emisores en suelos con un contenido de agua cerca de capacidad de campo (Coelho et al., 2007).

Otra manera de paliar la obturación, la estudiada en esta investigación, es adherir directamente sobre la manta (material textil) imprimaciones de sustancias químicas repelentes del crecimiento radicular. Éste no se ve afectado por dichas sustancias, de tal manera que se evita la invasión de raíces en los emisores.

Estas imprimaciones tienen dos principales inconvenientes, el impacto ambiental que pueden generar, tanto en el cultivo como en el medio, y el costo del material textil. Una posible alternativa para reducir el posible impacto ocasionado, es la utilización de imprimaciones naturales como puede ser la de fécula de maíz. A su vez, en relación al coste del material, este se puede reducir utilizando material reciclable.

Asimismo, los autores del presente estudio vienen investigando el uso de mantas de riego elaboradas a partir de material reciclable (moqueta ferial), pretendiendo así reducir el coste de las mismas y alargar la vida útil del material reciclado (Pérez, 2018, Ayudas para realizar proyectos de I+D convocatoria 2017, 2017). Un prototipo de los estudiados en las investigaciones precedentes, es el escogido como manta de riego de material reciclable para llevar a cabo la presente investigación.

Este aspecto cobra gran importancia teniendo en cuenta la problemática existente con respecto a la contaminación ambiental, y en concreto a la generación de plásticos. La producción global de plásticos ha aumentado de manera muy notable en los últimos 50 años, y en especial en las últimas décadas. Estos incrementos en la producción de residuos plásticos hacen que en 2015, en los océanos flotaran en torno a 5 billones de trozos de plástico. (FAO, 2015). Por tanto, se estima que en 2020 se superaren los 500 millones de toneladas anuales, lo que supondría un $900 \%$ más que los niveles de 1980. (Fernández, et al, 2019).

Por ello, es importante tener presente el concepto de Economía Circular. Este se apoya en los fundamentos de la escuela ecologista, y propone un cambio al paradigma "reducir, reutilizar y reciclar" por una transformación más profunda y duradera, que permita disminuir el impacto causado por las actividades humanas sobre el medio ambiente. Este modelo otorga al residuo un papel dominante y se sustenta en la reutilización inteligente del desperdicio, sea este de naturaleza orgánica o de origen tecnológico, en un modelo cíclico que imita a la naturaleza y se conecta con ella. Bajo este enfoque, el residuo pierde su condición de tal y se convierte en la materia prima o se transforma para formar parte de nuevos productos tecnológicos, con un mínimo gasto energético (Felber, 2011; Lett, 2014;). 


\section{CONGRESO IBÉRICO DE AGROINGENIERÍA \\ X CONGRESSO IBÉRICO DE AGROENGENHARIA \\ 3 - 6 septiembre 2019, Huesca - España}

La presente investigación tiene como principal objetivo evaluar las diferentes imprimaciones de sustancias químicas como repelente radicular en prototipos de mantas de riego subsuperficial confeccionadas a partir de material reciclable.

A lo largo del tiempo se han ido investigando diversos métodos para paliar dicha obstrucción. Unas de las sustancias químicas estudiadas con detalle ha sido la Trifluralina, materia activa de algunos herbicidas utilizados en agricultura. Su mecanismo de acción afecta a la división celular en los tejidos meristemáticos, inhibiendo la formación de nuevas células en la raíz y el tallo (Rodrigues, et al, 2010). Esto hace que se impida, o se reduzca, la intrusión de las raíces de los cultivos en los emisores de riego.

\section{Materiales y métodos}

\subsection{Prototipos manta-imprimación a evaluar}

Las sustancias químicas utilizadas en las imprimaciones han sido; mezcla de látex con fécula de maíz, a diferentes concentraciones (" $\mathrm{E}$ ", " $\mathrm{F}$ " y "G") y nanopartículas. A modo de testigos se evalúan dos productos comerciales, Pendimetalina y Sulfato de Cobre. Además, se incorpora un tercer testigo el cual no ha sido sometido a envejecimiento, ni tampoco se le ha añadido ninguna imprimación.

A continuación, se muestran las formulaciones de cada una de las imprimaciones estudiadas:

\section{Imprimación tipo "E":}

- Almidón modificado $<4 \%$

- Conservante tipo HHT $<0,1 \%$

- Látex Vinílico $<25 \%$

- Conservante tipo MIT <0,1\%

- Otros componentes: productos espesantes naturales, antiespumantes y aditivos en pequeñas dosificaciones

\section{Imprimación tipo "F":}

- Almidón modificado $<2,5 \%$

- Conservante tipo HHT $<0,08 \%$

- Látex Vinílico $<26 \%$

- Conservante tipo MIT $<0,15 \%$

- Otros componentes: productos espesantes naturales, antiespumantes y aditivos en pequeñas dosificaciones

\section{Imprimación tipo “ $G$ ":}

- Almidón modificado $<2 \%$

- Conservante tipo HHT $<0,06 \%$

- Látex Vinílico $<27 \%$

- Conservante tipo MIT <0,2\%

- Otros componentes: productos espesantes naturales, antiespumantes y aditivos en pequeñas dosificaciones

Así pues, todas las sustancias han sido imprimadas sobre sendos prototipos de mantas de riego subsuperficial (ver Figura 1). 


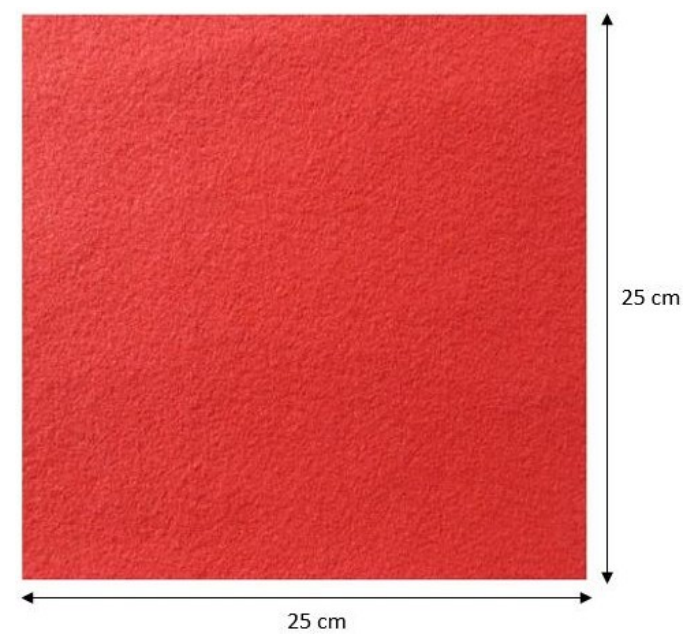

Figura 1. Prototipo de manta de riego de aproximadamente $25 \times 25 \mathrm{~cm}$.

Antes de comenzar con la experimentación en campo, con el fin de evaluar la posible atenuación del efecto como repelente radicular de cada imprimación por un uso continuado, se ha sometido a cada unidad manta-imprimación a un "envejecimiento" inducido. Esto último se ha llevado a cabo, sometiendo el material (manta-imprimación) a $100^{\circ} \mathrm{C}$ durante los diferentes periodos de tiempo, de tal manera de inducir 4 grados de deterioro o envejecimiento del material en cámaras $(5,10,15$ y 20 años). Todo este proceso se ha repetido, a su vez, en dos condiciones contrastantes de humedad: húmedo y seco (ver Figura 2).
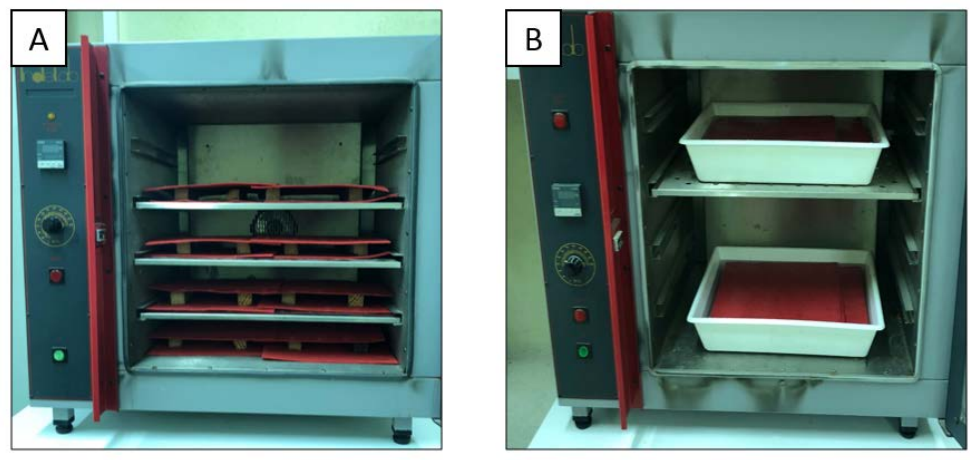

Figura 2. Muestras del material textil en cámaras bajo las condiciones de A) seco y B) sumergidas en agua.

\subsection{Diseño experimental}

La presente investigación no se ha realizado con mantas de riego subterráneas imprimadas. Si fuera así el ensayo, se cuantificarían las raíces que han atravesado la manta del exterior al interior donde se encuentra el tubo de riego. Sin embargo, en lugar de dicha metodología se han confeccionado sendos "sobres" a modo de macetas, cosidos a mano, con las diferentes imprimaciones a evaluar (ver Figura 3 y Figura 4).

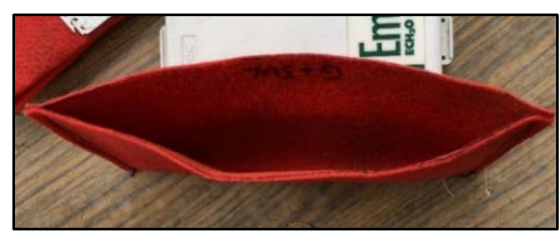

Figura 3. Imagen de una de las muestras de material textil (polipropileno) tras realizar el cosido 


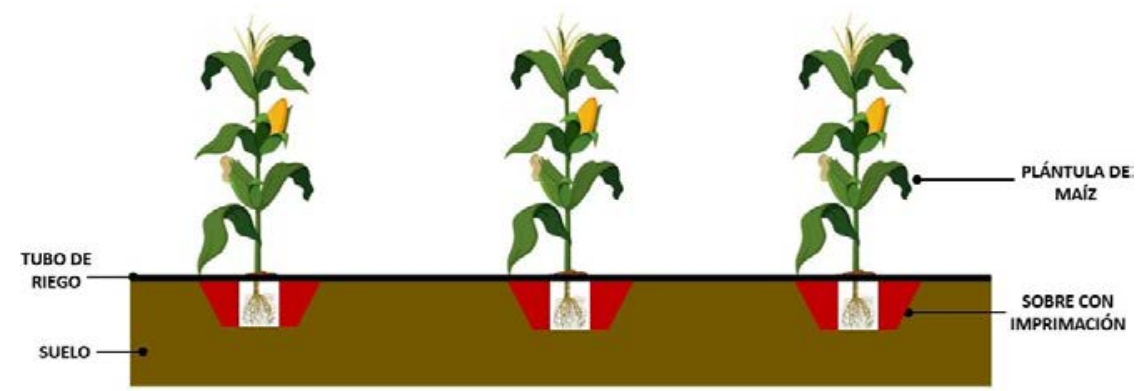

Figura 4. Detalle del esquema general de la experimentación.

Como consecuencia de la combinación de las diferentes imprimaciones, con el tiempo de envejecimiento del material textil por temperatura y según si dicho envejecimiento se da en seco o en agua, surgen un total de 96 tratamientos diferentes a estudiar (ver Figura 5).

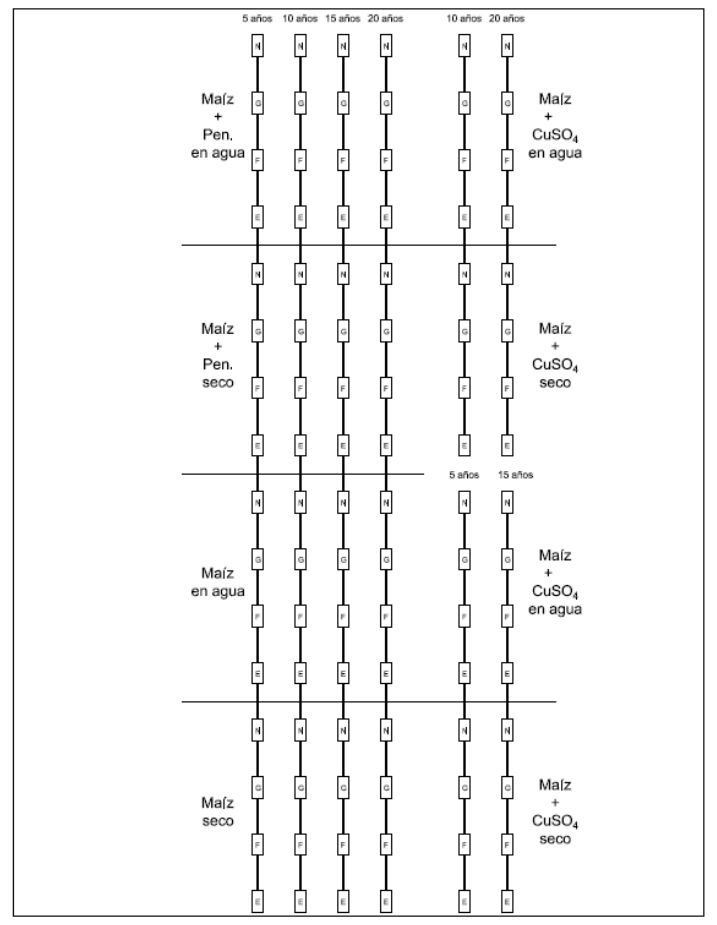

Figura 5. Esquema general del diseño experimental. Cada recuadro corresponde a un tratamiento.

Estos sobres se han rellenado con suelo a capacidad de campo el cual mediante un proceso de desmenuzado a mano pasa a ser tierra fina, con textura semejante a una cama de siembra. Esto permite un mayor contacto entre el suelo y la semilla, lo que facilita el desarrollo de la misma. Para poder ver el efecto que tienen las distintas imprimaciones, es necesario emplear un cultivo con raíces fuertes y rápido enraizamiento, por lo que se ha decidido sembrar maíz.

Antes de implantar los tratamientos en el suelo se debe llevar a cabo una preparación del terreno. En este caso, se remueve el suelo con un apero tradicional de labranza.

Una vez que el terreno ha sido preparado, se han abierto diferentes zanjas en el suelo con ayuda de una azada, en las que se entierran las macetas a ras de suelo (ver Figura 6). Asimismo, es importante compactar el suelo que linda con cada uno de los sobres, para facilitar el contacto entre ambos. 


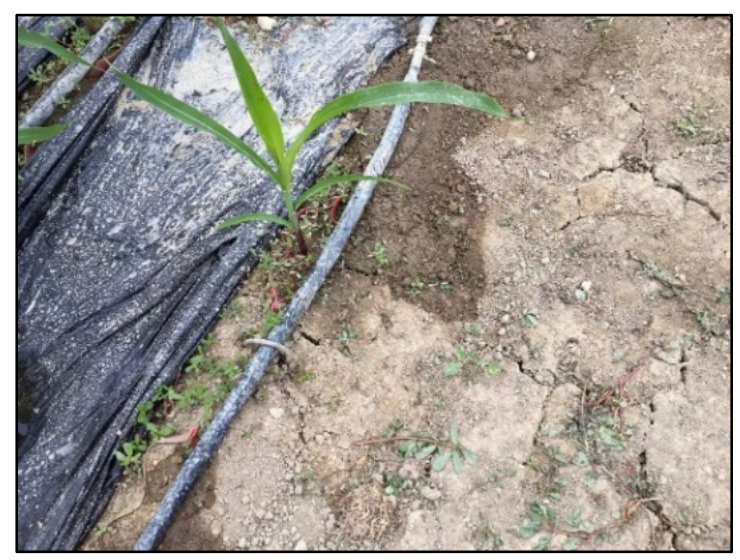

Figura 6. Imagen de una de las bolsas enterradas en el invernadero.

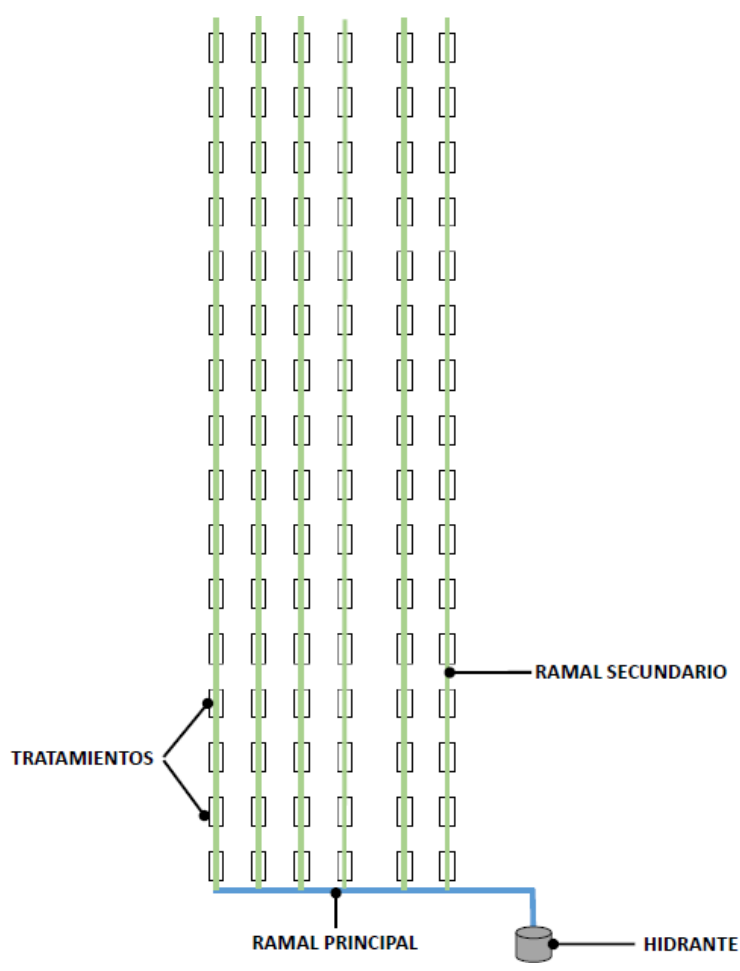

Figura 7. Esquema de la instalación del sistema de riego.

En lo referente al sistema de riego, se trata de una instalación sencilla (ver Figura 7) que presenta un ramal principal del cual salen otros seis ramales secundarios que alimentan cada uno de los tratamientos. El ramal principal está conectado a la bomba de salida, ubicada en el lateral derecho del mismo invernadero donde se desarrolla el ensayo, llevando un caudal de $2 \mathrm{l} / \mathrm{h}$.

Para el correcto desarrollo del material vegetal, se han determinado las necesidades hídricas del cultivo y tras ello, se ha procedido a la obtención de los tiempos de riego para los meses de abril a septiembre.

\subsection{Protocolo experimental}

Una vez que la planta alcanza su madurez, la maceta se desentierra y fotografía la parte aérea de la planta (ver Figura 8) y se pesa todo el material vegetal extraído. 


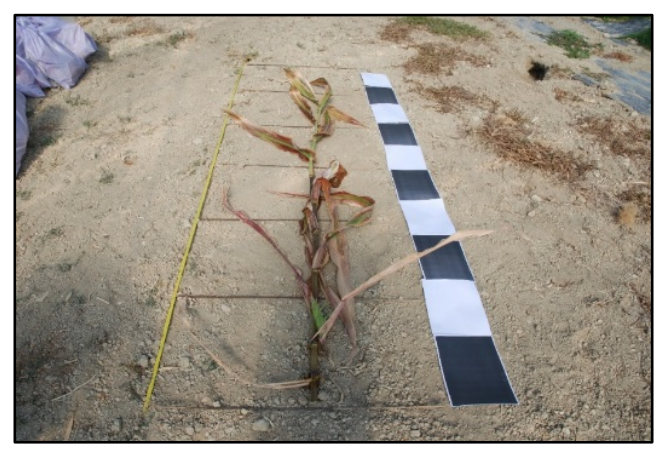

Figura 8. Ejemplo de toma de fotografía de la parte aérea de la planta de maíz.

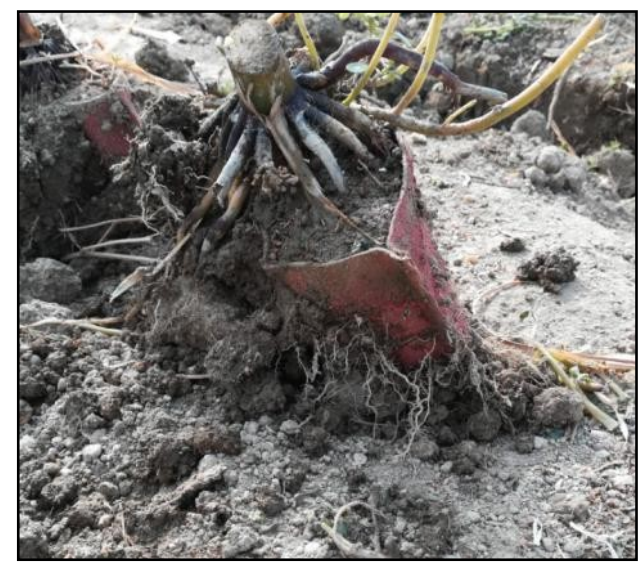

Figura 9. Sobre con la parte radicular de la planta de maíz desenterrado.

Del mismo modo, la parte radicular de cada planta, es decir, el tocón, se desentierra con la maceta (ver Figura 9), y se pesa.

Posteriormente, se lleva a cabo la separación del tocón del sobre. Para ello, en primer lugar se elimina cuidadosamente con la ayuda de una espátula, la porción de suelo adherida a la parte exterior del sobre. Tras ello, mediante el empleo de un cúter, se descosen los laterales del sobre y se extrae el tocón del mismo (ver Figura 10). De esta manera, es posible observar claramente si las raíces han atravesado la moqueta (ver Figura 11).

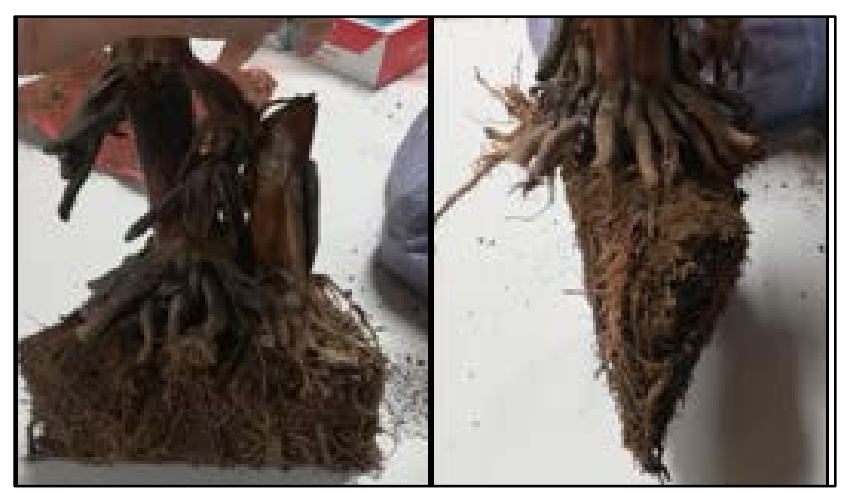

Figura 10. El tocón una vez quitado el material textil. 


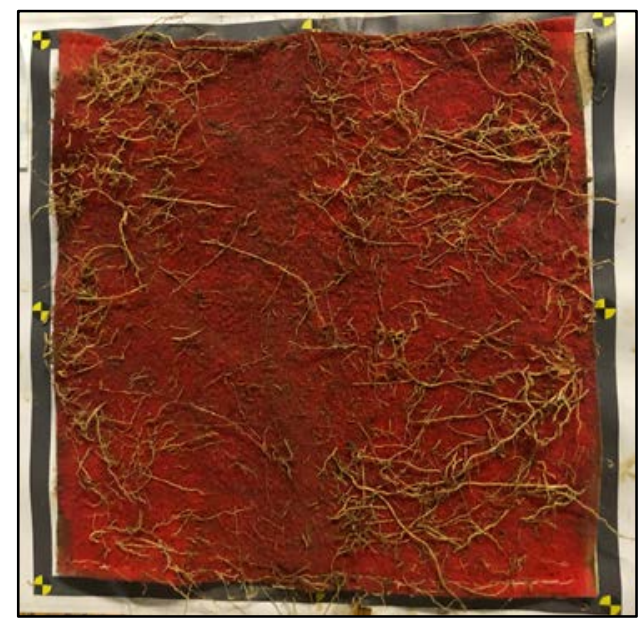

Figura 11. Detalle de la bolsa tras haber descosido los laterales. Se observan las raíces que la han atravesado.

Finalmente, con todos los sobres limpios, se evalúa la superficie del sobre que está ocupada por las raíces y que han atravesado el material, para poder así valorar el efecto de las imprimaciones. A mayor superficie ocupada por las raíces, menor efecto de la imprimación aplicada. Esto se realiza mediante la toma de fotografías de cada uno de los tratamientos y su posterior análisis a través de la herramienta informática Qgis.

El estudio se ha llevado a cabo en las parcelas experimentales de la Finca de Prácticas de la Universidad Pública de Navarra (UPNA).

\subsection{Análisis de datos. Processado de imágenes.}

Tal y como se ha mencionado en el apartado anterior (ver arriba), el objetivo del procesado de imágenes es poder conocer la superficie radicular ocupada en cada uno de los tratamientos. Para ello, se ha decidido emplear el programa informático QGIS.

Así pues, los pasos clave para el análisis de imágenes son, en este orden, los siguientes:

(i) En primer lugar, se lleva a cabo la georrectificación de la imagen RGB, ya que la imagen obtenida no está tomada desde un ángulo totalmente perpendicular (ver Figura 12A),

(ii) Tras ello, se obtiene la imagen binaria, la cual permite identificar y cuantificar con claridad el total de las raíces presentes en la imagen (ver Figura 12B).

(iii) Seguidamente, la imagen binaria es dividida en cinco profundidades diferentes:

- Profundidad 1: de 0 a $2,5 \mathrm{~cm}$.

- Profundidad 2: de 2,5 a $5 \mathrm{~cm}$.

- Profundidad 3: de 5 a 7,5 cm.

- Profundidad 4: de 7,5 a $10 \mathrm{~cm}$.

- Profundidad 5: de 10 a 12,5 cm.

(iv) Finalmente, se determinan las variables estadísticas de media y desviación estándar, de cada una de las profundidades. 

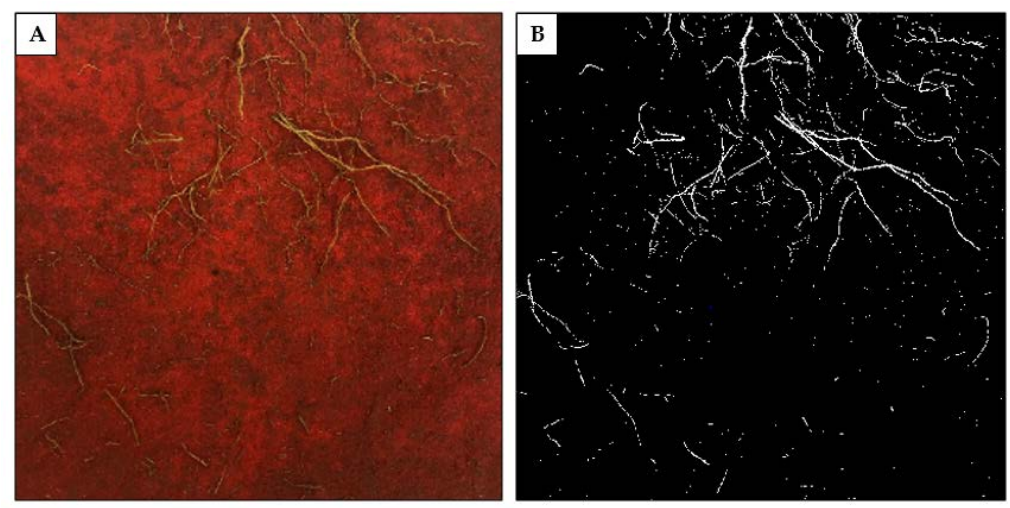

Figura 12. Ejemplo de las imágenes obtenidas durante su procesado en QGIS. A) Imagen tras la georreferenciación y B) Imagen binaria.

Se destaca que, con los datos estadísticos obtenidos tras el procesado de imágenes, se ha efectuado un análisis de la varianza (ANOVA) de los distintos factores, como son el envejecimiento del material, tanto por temperatura como por grado de humedad del mismo, las diferentes profundidades que se encuentran en cada sobre y las imprimaciones. Además, se ha hecho uso del test de Tukey para ver que imprimación es la que mayor efecto tiene a la hora de repeler el crecimiento radicular.

Es importante mencionar que, la investigación se ha basado en el supuesto de que el volumen ocupado por las raíces en cada tratamiento está linealmente relacionado con el número de raíces presentes en cada uno de ellos. Para poder conocer si esta hipótesis inicial es cierta, se ha cuantificado el número de raíces que han atravesado el sobre en un área conocida. Para ello, primeramente, se seleccionan 7 tratamientos con diferentes grados de densidad radicular, es decir: alta, media y baja. Después, se delimita un área de aproximadamente 7,6 x 7,6 cm en cada tratamiento. Tras ello, se fotografía el área marcada en el sobre y se realiza el mismo procesamiento de imagen de acuerda al protocolo descrito anteriormente (ver arriba). A continuación, se extraen cuidadosamente, empleado una pinza de laboratorio, las raíces contenidas en su interior y se contabilizan.

Una vez se ha cuantificado la superficie ocupada por las raíces en el área delimitada y se han contabilizado el número de raíces presentes en dicho área, se grafican los datos obtenidos y se comprueba si realmente existe un relación lineal entre ambos.

Finalmente, se desea mencionar que debido los diferentes periodos de deterioro o envejecimiento del material, no se han sembrado todos los sobres al mismo tiempo. Además, debido a las altas temperaturas que se han acumulado en los inverderos de la UPNA durante los meses de primavera y verano 2018, ha habido grandes problemas de germinación, provocando que los tratamientos no tengan la misma fecha de siembra. Tanto es así que, ha habido 4 tratamientos de los 96 en los que no se ha conseguido su germinación.

\section{Resultados y discusión}

Como ya se ha comentado, la investigación cuenta con dos imprimaciones a modo de testigos, que son la Pendimetalina y el Sulfato de Cobre. Observando los datos tanto de la superficie ocupada por raíces como el peso de los tocones de los tratamientos con Sulfato de Cobre, estos son notablemente menores que el resto de tratamientos. Esto sería debido a que la siembra de estos testigos fue más tardía que el resto de tratamientos y no a la acción repelente de la imprimación (ver Figura 13). Por tanto, se decide descartar el testigo con Sulfato de Cobre en nuestra evaluación. 


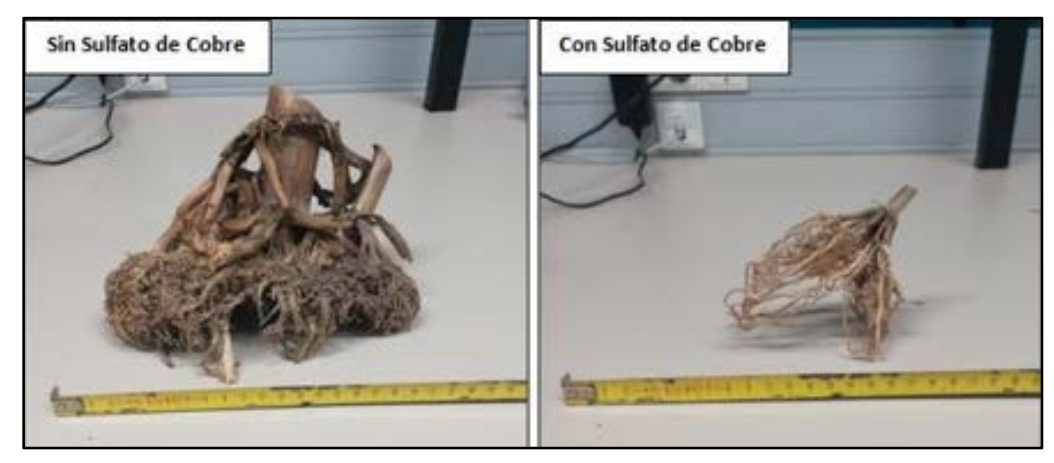

Figura 13. Ejemplo del menor desarrollo radicular alcanzado por los tratamientos testigos con sulfato de cobre (derecha) con respecto a los restantes tratamientos (izquierda) debido a la siembra tardía de los primeros.

Otro punto importante a resaltar es que la hipótesis de que la superficie del material textil ocupada por las raíces es un buen estimador del número de raíces, es aceptable. Esto se aprecia en la Gráfica 1, donde se ve como la superficie ocupada por las raíces es directamente proporcional (función lineal) al número de las mismas.

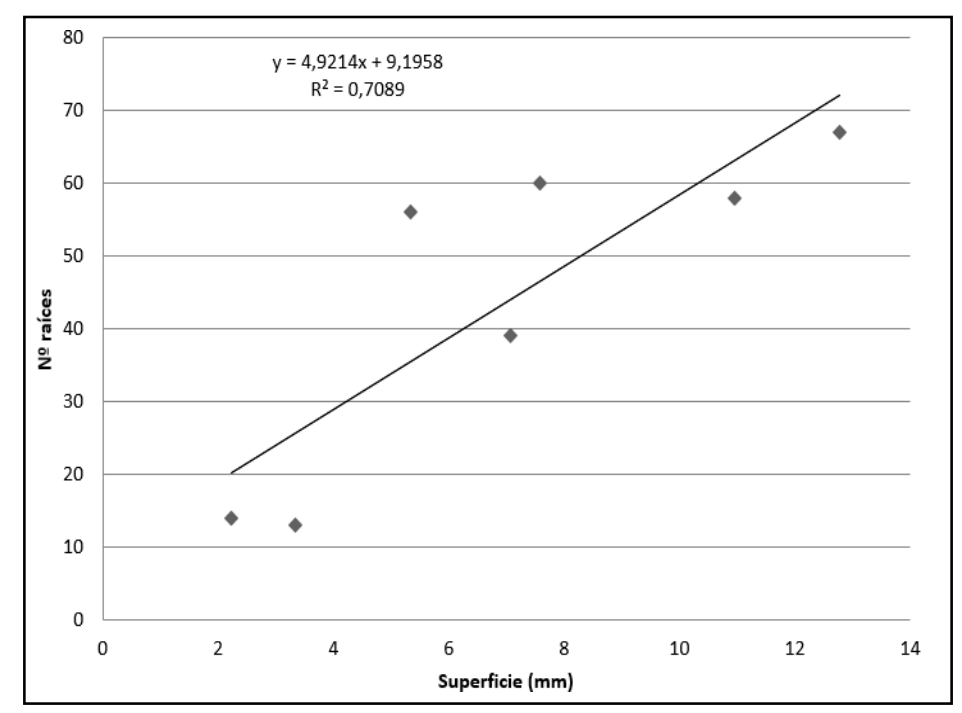

Gráfica 1. Relación existente entre la superficie ocupada por las raíces y el número de las mismas.

Se comienza realizando un análisis de la varianza reagrupando todos los tratamientos según sólo el grado de humedecimiento en su preparación: "húmedo" y "seco". No se observan diferencias significativas entre las dos poblaciones (húmedo y seco) (ver Tabla 1).

Tabla 1. ANOVA de los tratamientos reagrupados en "húmedo" y "seco".

\begin{tabular}{ccccccc}
\hline $\begin{array}{c}\text { Origen de las } \\
\text { variaciones }\end{array}$ & $\begin{array}{c}\text { Suma de } \\
\text { cuadrados }\end{array}$ & $\begin{array}{c}\text { Grados de } \\
\text { libertad }\end{array}$ & $\begin{array}{c}\text { Promedio de los } \\
\text { cuadrados }\end{array}$ & F & $\begin{array}{c}\text { ProbabilidadValor crítico } \\
\text { para F }\end{array}$ \\
\hline $\begin{array}{c}\text { Entre grupos } \\
\text { Dentro de los }\end{array}$ & 0,0007 & 1,0 & 0,0007 & 2,9868 & 0,0846 & 3,8628 \\
grupos & 0,1052 & 438,0 & 0,0002 & & & \\
\hline Total & 0,1059 & 439,0 & & & & \\
\hline
\end{tabular}




\section{CONGRESO IBÉRICO DE AGROINGENIERÍA \\ X CONGRESSO IBÉRICO DE AGROENGENHARIA \\ 3 - 6 septiembre 2019, Huesca - España}

Así pues, se elige el grupo de tratamientos en húmedo ya que serían los más representativos de las condiciones de trabajo (mantas de riego subsuperficial).

A continuación, se continúa con el estudio realizando un análisis de la varianza discriminado por el grado de envejecimiento de la moqueta con la imprimación. En este caso, se hallan diferencias significativas entre las poblaciones de tratamientos (ver Tabla 2). Es por ello por lo que se realiza un test de Tukey para comparar los diferentes grados de envejecimiento (ver Tabla 3).

Tabla 2. ANOVA de los tratamientos discriminados por el grado de envejecimiento.

\begin{tabular}{ccccccc}
\hline $\begin{array}{c}\text { Origen de las } \\
\text { variaciones }\end{array}$ & $\begin{array}{c}\text { Suma de } \\
\text { cuadrados }\end{array}$ & $\begin{array}{c}\text { Grados de Promedio de los } \\
\text { libertad }\end{array}$ & cuadrados & F & Probabilidad & $\begin{array}{c}\text { Valor } \\
\text { crítico } \\
\text { para F }\end{array}$ \\
\hline $\begin{array}{c}\text { Entre grupos } \\
\begin{array}{c}\text { Dentro de los } \\
\text { grupos }\end{array}\end{array}$ & 0,0006 & 3 & 0,0000 & 7,4906 & 0,0024 & 3,2389 \\
\hline Total & 0,0010 & 16 & 0,0000 & & & \\
\hline
\end{tabular}

Tabla 3. Test de Tukey de los tratamientos en función del grado de envejecimiento (5, 10, 15 y 20 años).

\begin{tabular}{|c|c|c|c|c|}
\hline & 5 AÑOS & 10 AÑOS & 15 AÑOS & 20 AÑOS \\
\hline 5 AÑOS & & $0,0007^{*}$ & $0,0084^{*}$ & 0,01200 \\
\hline 10 AÑOS & & & $0,0092^{*}$ & 0,0127 \\
\hline 15 AÑOS & & & & $0,0036^{*}$ \\
\hline 20 AÑOS & & & & \\
\hline
\end{tabular}

*Existen diferencias significativas.

Observando los datos obtenidos en el test de Tukey (ver Tabla 3) se percibe como no hay una tendencia sistemática de variación en los tratamientos de los diferentes años de envejecimiento.

Por tanto, se continúa el análisis con el grupo de tratamientos de menor deterioro inducido (5 años) ya que en la práctica la vida útil de las mantas de riego estaría también en este rango de tiempo.

Finalmente, se procede a evaluar el efecto de las diferentes imprimaciones (E, F, G, N, etc.) a partir de un ANOVA de dos factores; siendo el segundo factor la profundidad de enraizamiento (ver Tabla 4). Se observan diferencias significativas tanto entre columnas (imprimaciones) como entre filas (profundidad).

Tabla 4. ANOVA de dos factores: las imprimaciones y la profundidad.

\begin{tabular}{ccccccc}
\hline $\begin{array}{c}\text { Origen de las } \\
\text { variaciones }\end{array}$ & $\begin{array}{c}\text { Suma de } \\
\text { cuadrados }\end{array}$ & $\begin{array}{c}\text { Grados de } \\
\text { libertad }\end{array}$ & $\begin{array}{c}\text { Promedio de } \\
\text { los cuadrados }\end{array}$ & F & Probabilidad & $\begin{array}{c}\text { Valor } \\
\text { crítico } \\
\text { para F }\end{array}$ \\
\hline $\begin{array}{c}\text { Filas } \\
\text { (PROFUNDIDAD) } \\
\text { Columnas }\end{array}$ & 0,0021 & 4 & 0,0005 & 3,3014 & 0,0246 & 2,7141 \\
$\begin{array}{c}\text { (TRATAMIENTOS) } \\
\text { Error }\end{array}$ & 0,0129 & 7 & 0,0018 & 11,8985 & 0,0000 & 2,3593 \\
\hline Total & 0,0044 & 28 & 0,0002 & & & \\
\hline
\end{tabular}




\section{CONGRESO IBÉRICO DE AGROINGENIERÍA \\ X CONGRESSO IBÉRICO DE AGROENGENHARIA \\ 3 - 6 septiembre 2019, Huesca - España}

Para finalizar con el estudio estadístico y poder estimar que imprimación es la que mejor efecto tiene sobre el crecimiento radicular, se elabora un test de Tukey en el cual se comparan los tratamientos de envejecimiento 5 años y húmedo y los datos correspondientes a la profundidad $3(5-7,5 \mathrm{~cm})$ (ver Tabla 5). La selección de esta profundidad se basa en el hecho de que el mayor crecimiento radicular en todos los tratamientos se ha observado precisamente en dicho rango de profundidad.

Tabla 5. Test de Tukey de los tratamientos "húmedos" y " 5 años".

\begin{tabular}{|c|c|c|c|c|c|c|c|c|}
\hline & $\mathrm{E}$ & $F$ & G & $\mathbf{N}$ & Pen_E & Pen_F & Pen_G & Pen_N \\
\hline $\mathrm{E}$ & & 0,017 & 0,01 & 0,026 & 0,023 & 0,001 & 0,026 & 0,0313 \\
\hline F & & & 0,007 & 0,008 & 0,006 & 0,016 & 0,009 & $0,0484^{*}$ \\
\hline G & & & & 0,016 & 0,013 & 0,009 & 0,016 & $0,0412^{*}$ \\
\hline $\mathbf{N}$ & & & & & 0,003 & 0,025 & 0,0004 & $0,0568^{*}$ \\
\hline M+Pen_E & & & & & & 0,022 & 0,003 & $0,0542^{*}$ \\
\hline M+Pen_F & & & & & & & 0,025 & $0,0324^{*}$ \\
\hline M+Pen_G & & & & & & & & 0,0171 \\
\hline $\mathbf{M}+$ Pen_N & & & & & & & & \\
\hline
\end{tabular}

*Existen diferencias significativas.

Los resultados del test de Tukey (ver Tabla 5), muestran que los tratamientos con imprimación tipo " $\mathrm{N}$ " (nanopartículas) presentan un comportamiento superior, aunque no muy marcado, a su equivalente comercial. Las restantes imprimaciones (fécula de maíz + látex en diferentes concentraciones), no han mostrado un mejor comportamiento con respecto a sus respectivos testigos. Por lo tanto, se concluye que la imprimación $\mathrm{N}$ es la más efectiva como repelente radicular.

\section{Conclusiones}

El grado de obturación de emisores ubicados dentro de mantas de riego subsuperficial podría reducirse con imprimaciones de sustancias inocuas al medio ambiente que actúan como repelente radicular. Estas sustancias operarían al menos con la misma efectividad que la lograda con otros repelentes comerciales de síntesis, pero de posible impacto ambiental.

Los primeros resultados de la experimentación muestran que solamente los tratamientos con imprimación tipo "N" (nanopartículas) presentaron un comportamiento superior -aunque no muy marcado- a su equivalente comercial. Las restantes imprimaciones (fécula de maíz+ látex en diferentes concentraciones), no mostraron un mejor comportamiento con respecto a sus respectivos testigos.

La actuación del mejor prototipo de imprimación evaluado (tipo “N”) podría incluso superarse usándose a mayores concentraciones. Se recomienda investigar esta posibilidad.

Esta imprimación mantendría su efecto repelente durante al menos la vida útil de la propia manta de riego (años).

Las imprimaciones que no superaron al testigo comercial, no son descartadas. Futuras investigaciones podrían demostrar que su limitado efecto repelente es, no obstante, suficiente para reducir el grado de obturación de los emisores a valores aceptables.

Se hace necesario investigar el grado de protección que la manta de riego per se - sólo como barrera física- ejerce sobre los emisores. De hecho, se ha incorporado recientemente a la presente experimentación un nuevo testigo sin imprimación ni tratamiento previo.

Se ha implementado con éxito una innovadora técnica semiautomática de conteo de raíces. 


\section{CONGRESO IBÉRICO DE AGROINGENIERÍA \\ X CONGRESSO IBÉRICO DE AGROENGENHARIA \\ 3- 6 septiembre 2019, Huesca - España}

\section{Referencias}

1. Ayars, J.E., Phene, C.J, Hutmacher, R.B., Davis, K.R., Schoneman, R.A., Vail, S.S. y Mead R.M. (1999). Subsurface drip irrigation of row crops: a review of 15 years research at the Water Management Research Laboratory. Agric. Water Manage.

2. Ayudas para realizar proyectos de I+D convocatoria 2017. Proyectos en colaboración o de transferencia del conocimiento de Gobiernos de Navarra. 2017. HIDROCEL: 001-1365-2017-000182.

3. Coelho, R., Faria, L., y de Mélo, R. (2007). Obstrução de gotejadores autocompensantes enterrados na irrigação de citros causada por intrusão radicular obstruction of self-compensated emitters in subsurface drip citrus irrigation (root intrusion-sdi).

4. Felber, C. (2011). La Economía del Bien Común/ L'economía Bene Comune. Disponible en: https://www.youtube.com/watch?v=U4tL4eS--XM

5. Fernández Izard, M., Escudero Bocos, C., Toril Moreno, R., Antolin García, T., García Valcárcel, C., Herranz Aparicio, G., Matesanz Miguel, I. y Moreno Rodríguez, A. (2019). Día mundial de la educación ambiental. Disponible en: https://www.miteco.gob.es/es/ceneam/recursos/pag-web/dia-mundial-eaguia-recursos-2019_tcm30-375733.pdf [Accessed 13 May 2019].

6. Lett, L. A. (2014). Las amenazas globales, el reciclaje de residuos y el concepto de economía circular. Revista argentina de microbiología, 46(1), 1-2. Disponible en: file://I:/TFM/Propuesta\%20TFM/Artículo.pdf

7. Martin de Santa Olalla,F. y De Juan, J.A. 1993. Agronomia del riego. Mundi-Prensa, Madrid, p. 732.

8. Pérez, B. (2018). Evaluación de mantas de riego subsuperficial realizadas con material reciclado para su aplicación en cubiertas vegetales. Pamplona: Universidad Pública de Navarra.

9. Rodrigues, B. N., Lima, J. de, Yada, I. F. U., \& Fornarolli, D. A. (2010). Influência da cobertura morta no comportamento do herbicida sulfentrazone. Planta Daninha, 17(3), 445-458. Disponible en: https://doi.org/10.1590/s0100-83581999000300011 